Commentary

\title{
Saving the starfish: World Federation of Pediatric Imaging (WFPI) \\ development, work to date, and membership feedback on international \\ outreach
}

Amanda Dehaye ${ }^{1}$

Cicero T. Silva ${ }^{2}$

Kassa Darge ${ }^{3}$

Sanjay P. Prabhu ${ }^{4}$

Savvas Andronikou 5

Bernard F. Laya ${ }^{6}$

Brian D. Coley $^{7}$

Maria Ines Boechat ${ }^{8}$

$\triangle$ Maria Ines Boechat

iboechat@mednet.ucla.edu

${ }^{1}$ World Federation of Pediatric Imaging (WFPI), Pau, France

${ }^{2}$ Department of Radiology \& Biomedical Imaging, Yale School of Medicine, New Haven, CT, USA

${ }^{3}$ Department of Radiology, The Children's Hospital of Philadelphia, Perelman School of Medicine, University of Pennsylvania, Philadelphia, PA, USA

${ }^{4}$ Department of Radiology, Boston Children's Hospital, Boston, MA, USA

${ }^{5}$ Bristol Royal Hospital for Children, Bristol, UK

${ }^{6}$ St. Luke’s Medical Center, Taguig City, Philippines

${ }^{7}$ Department of Radiology and Medical Imaging,

Cincinnati Children's Hospital Medical Center, Cincinnati, OH, USA

${ }^{8}$ Department of Radiological Sciences, Department of Pediatrics, University of California, Los Angeles, Department of Radiology, David Geffen School of Medicine at UCLA, CHS B2-252, 10833 Le Conte Ave., Los Angeles, CA 90095, USA 


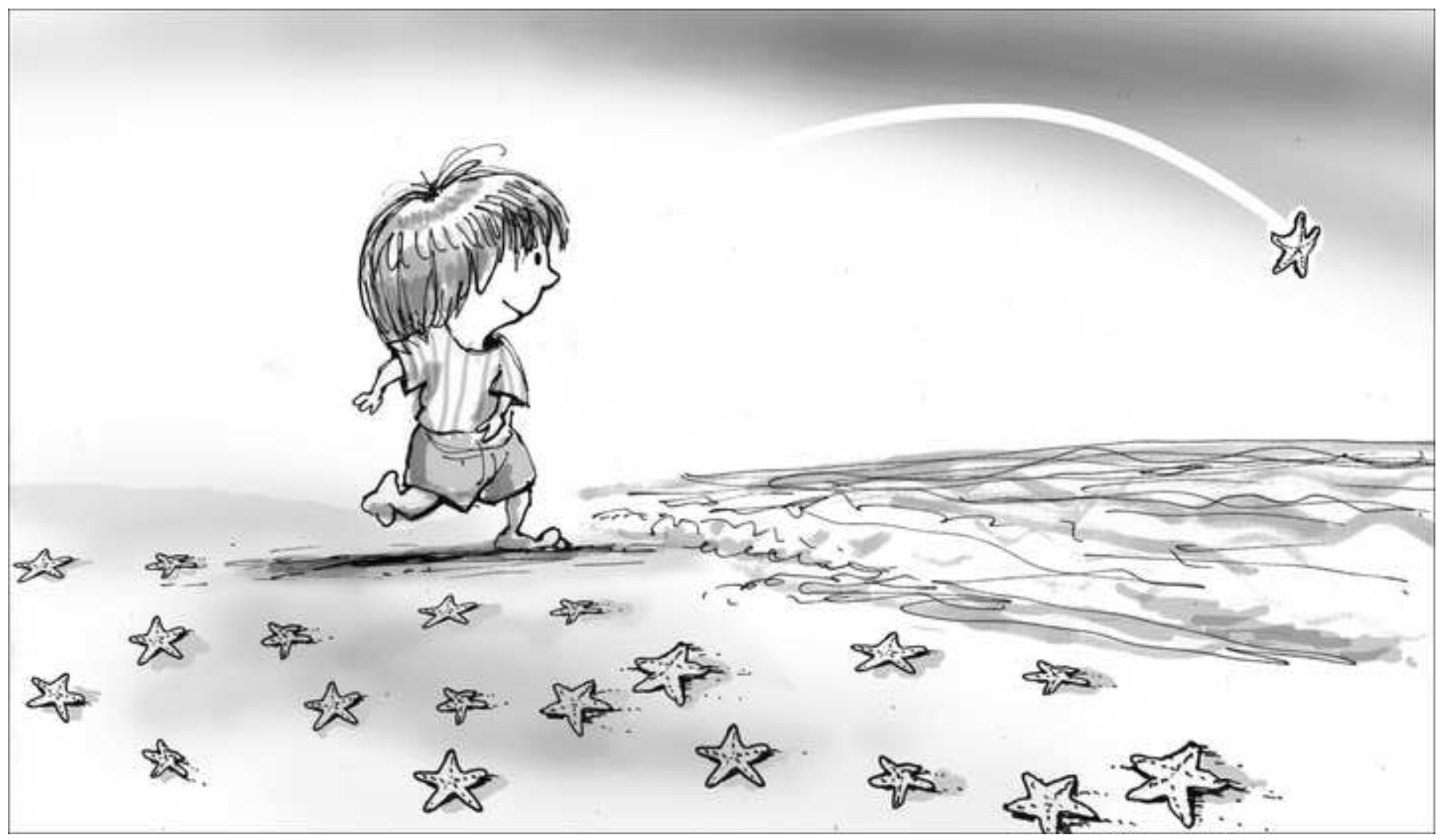


(Fig. 1)

Once upon a time there was an old man who used to take regular walks on the beach. One day, after a big storm, he found the beach littered with starfish as far as the eye could see. Then he noticed a small boy who kept bending down to pick up an object and throw it into the sea. "Good morning!" the old man called out. "May I ask what you are doing?" The young boy called back: "Throwing starfish into the sea. The tide has washed them up onto the beach and they're stuck. When the sun gets high, they'll die unless I throw them back." The old man replied, "But there must be tens of thousands of starfish on this beach. I'm afraid you won't make much of a difference." The boy bent down, picked up yet another starfish and threw it as far as he could into the sea. Then he turned, smiled and said, "I made a difference to that one!" [1]

Five years ago the leaders of the world's regional pediatric imaging societies launched the World Federation of Pediatric Imaging (WFPI). Its founders had a variety of opinions on what form and mandate it should take; after all, establishing workable governance and clear added value is a daunting task for any international organization starting out [2-4]. By 2012, however, two firmly held convictions — that there is a need for a louder pediatric voice in the imaging arena, and that strength lies in numbers — led to this mission statement: "WFPI provides an international platform for pediatric radiology organizations united to address the challenges in global pediatric imaging training and the delivery of services." Setting up its governing body in 2012 [5], WFPI went on to prioritize "Communication and collaboration between pediatric imaging practitioners, via their organizations" to achieve its goals [6]. With limited resources and a loose working mandate, WFPI set about carving its niche, drawing heavily on those among its members with developing-world experience. 
By late 2015, the progress was tangible. Nonetheless, translating high-reaching global ambitions into meaningful actions while surmounting geographic, temporal, cultural and linguistic distances is hard work. Is it all worth it?

\section{Together, more starfish can be saved}

WFPI's mandate and governance should reflect the wishes of its membership. As such, WFPI's regional member society boards were called upon in early 2014 to assess WFPI's trajectory to date. These boards largely reported that the creation of WFPI was the right way to go, both in its inclusive structural set-up (all five regions with equal voting weight) and in its aims of providing a united front, facilitating the sharing of expertise and raising awareness of the multiple needs of pediatric imaging [7]. In terms of a mandate, online education was largely favored, as was support for work in lower-resource settings crippled by high disease burdens in large pediatric populations.

What did the individual members of these regional societies think? In March 2014, the Society for Pediatric Radiology (SPR) polled its members on international outreach efforts. Of the 273 SPR respondents (23\% response rate: $85 \%$ complete, $15 \%$ partial), $79 \%$ approved of "WFPI being something SPR should continue to pursue." Those who disapproved pointed to the disparate nature of existing international efforts, suggesting that WFPI "adds another set to the alphabet soup."

A large majority of SPR survey respondents also supported intrinsic international efforts. A number of WFPI member organizations already do just this — the Rwanda ultrasound courses supported by the Société Francophone d'Imagerie Pédiatrique and the Swaziland teaching visit run by the South African Society of Paediatric Imaging (SASPI), to cite but two. Furthermore, institutions run international pediatric imaging initiatives among others, the Graz University Hospital, Austria, teaches in Eastern Europe, Toronto's 
Hospital for Sick Children, Canada, teaches in India, and the Children's Hospital of Philadelphia (CHOP), USA, offers a series of webinars in South Africa, in collaboration with the Radiological Society of South Africa and SASPI [8]. These initiatives might be seen as competition for - or a rejection of - WFPI. Not so. WFPI embraces and supports them. With its own resource limitations, it cannot run such projects itself — but these are starfish being saved!

The SPR survey also explored different configurations for fueling international work. Eighty-three percent of the 273 respondents approved the statement "WFPI should unite pediatric imaging societies around the world" while 77\% approved the statement "SPR should increase its involvement in other societies' international work." Concerns expressed about WFPI's development hinged upon reinvention of the wheel and WFPI's limited resources — and therefore capacity to impact — compared to other organizations.

Although most people would seem to agree that by corralling forces internationally, more starfish can be saved, the priorities and concerns expressed by our membership do merit reflection on WFPI's current lines of work, planned development, and guidelines for a future framework.

\section{Saving starfish: successes}

\section{Providing affordable online education worldwide}

The provision of free online education strikes a chord the world over. In 2015 WFPI and SPR launched an internationally coordinated online video library [9], reflecting WFPI's preferred educational approach of inputting expertise and tools, free of charge, for people with a wide spectrum of medical backgrounds who are interested in pediatric imaging (enabling others to make the starfish saves). With 13 videos posted so far, including a Spanish video, "Como realizar una radiografia de tórax de calidad en niños [How to make a quality chest radiograph in children]" the selection has attracted more than 9,400 views in 12 months from 140 
countries (Fig. 2).

The video library's steering committee plans to solicit short talks from lecturers at future pediatric radiology meetings such as the International Pediatric Radiology meeting in Chicago this year.

As Internet traffic moves away from laptops and desktops and onto handheld devices, WFPI's dissemination of educational material also relies on the social media and apps they can access. Social media outlets are allowing content creators the space to host their videos without charge while new companies allowing the sharing of anonymized case material are providing additional channels for distribution. WFPI's other popular offerings include Facebook posts and educational cases posted across Facebook, Twitter, Instagram and the website "Figure 1."

Reaching an average of more than 1,000 people per post on Facebook, online cases are an important part of WFPI's educational work. On an entirely different scale, we partnered with Radiopaedia [10] for the International Day of Radiology 2015 celebrations, theme pediatrics, to run a series of pediatric imaging cases from around the world. Radiopaedia, a free educational radiology resource with one of the web's largest collections of radiology cases and articles, used its massive social media presence (371,000 Facebook and 15,300 Twitter followers hailing from a range of medical fields) for dissemination, along with WFPI's own outlets and website. Cumulatively, the cases reached more than 2 million screens in 1 week, with a pediatric imaging cases playlist issued subsequently [11]. This shows that WFPI's educational materials can reach large numbers of interested learners through social media via strategic partnerships (Fig. 3).

We are exploring additional ways to expand our audiences, such as linking the "case of the week" to videos on the online library, cross-posting case material and developing videos based on a core curriculum. 
WFPI also uses its website — www.wfpiweb.org — as a platform to disseminate education to pediatric radiologists as well as other radiologists, radiographers and medical professionals who do not have special pediatric expertise. Currently the website serves mainly as the gateway to online video education offerings and educational cases, and as an information harbor for social media posts.

\section{Onsite teaching and training}

Onsite teaching and training, a priority for many members, was of particular interest in Europe at WFPI's outset. WFPI has prepared a set of guidelines [12] to increase the lasting impact from such visits, underpinned by recognition of both volunteers' limited time for immersion into local contexts, and common pitfalls such as the assumption that knowledge, skills and procedures acquired in high-resource centers are readily transferable, or even relevant, to low-resource settings [13].

The guidelines specify that WFPI seeks to "bolt on" to existing initiatives rather than set up tailored projects from scratch. The example of Lao Friends Hospital for Children, a new hospital set up and supported by Friends Without a Border and RAD-AID [14], illustrates WFPI's bolt-on approach. In May 2015, RAD-AID encouraged the Laos hospital to call on WFPI for tele-opinion support until its own imaging team was in place. It has since sent more than 300 studies to WFPI. A pediatric radiology fellowship program being conducted in Ethiopia - a country without a single pediatric radiologist for a population of 93 million people, of whom $60 \%$ are younger than 20 years [15] — also illustrates the benefits of bolting on. This project is organized and funded independently by the Addis Ababa University in collaboration with CHOP. Yet it is specifically run under the auspices of WFPI because its project leaders recognize the critical role WFPI can play in according such programs an international perspective, globally disseminating the tools developed [16], 
opening up networking and collaboration opportunities, and sharing lessons learned. And WFPI, by the mere fact of its organizational structure, offers recognition by an international pediatric radiology body. Forces have also been successfully joined with professional imaging societies (American College of Radiology in Haiti), other non-governmental organizations providing humanitarian medical aid (Médecins Sans Frontières/Doctors Without Borders in projects worldwide and Imaging the World for ultrasound work in Malawi and Uganda) as well as other institutions (University of California Los Angeles' Center for World Health in Mozambique).

These projects reflect further specifications set out in our WFPI guidelines: WFPIaffiliated outreach needs to be driven by engaged, onsite stakeholders with some degree of political/societal support, ready to work with international aid to catalyze changes that make sense for their realities, and that can be accepted and incorporated into a new medical/treatment culture. In sum, there is the need to identify partners and leverage points that can save a whole lot of starfish and facilitate change in the care provided by the people in the geographies involved.

It bears noting that in choosing to adopt this approach, WFPI differentiates itself from non-governmental organizations such as Imaging the World and Médecins Sans Frontières. WFPI — an international extension of professional imaging societies — can forge partnerships with, leverage, and bolt on to these organizations, but it cannot do what they do in terms of running entire projects themselves. WFPI simply does not have the contextual expertise and resource capacity (including funding) this demands. We must make purposeful choices in how we get involved (which means, at times, consciously saying "no") in fulfilling our mission to serve children.

\section{Tele-radiology}


Systematic reviews listed a number of advantages to tele-expertise services, including improved access to specialists and reduced traveling time and costs. But reservations have been voiced about its use by WFPI. Our limited resources demand careful calibration of our outreach aims, and tele-response times can be demanding. We have to choose which individual starfish we can save. Some physicians pinpoint the informatics and technology issues tele-expertise must confront, others query the legal situation. We also hear concerns about the external filling of staffing gaps and the limited opportunities tele-expertise provides for long-term improvements in the delivery of care onsite, echoed in an SPR respondent's comment that "Tele-radiology of overseas practices runs the risk of being paternalistic and impedes the growth and development as well as independence in those institutions."

Nonetheless, WFPI's provision of tele-expertise is underway. More than 500 studies were referred to WFPI from South Africa in 2013 [17], with 44 more from India in 2014 and 120 from Cambodia in 2014 and 2015. A rising number of tele-referrals have also been sent to pediatric radiologists via Médecins Sans Frontières: one WFPI specialist received more than 120 referrals in 2015 alone. Last, a further 330 studies have been referred to WFPI since 2014 via Collegium Telemedicus [18], the tele-platform WFPI now uses, largely from Laos (as well as Mozambique, Jamaica, India and Peru). Lao Friends Hospital for Children states that responses have been quick and useful; most have provided validation for its own diagnoses, others have offered additional ideas that were well received. As put by this hospital's executive director: "Just knowing that we can call on an expert pediatric radiologist anywhere in the world is a relief to us. It makes the world a little smaller and more cohesive" [19]. Data on our tele-platform use show the swift mobilization of WFPI's support at current referral levels. The 96 studies referred to WFPI in December 2015 were manually allocated to volunteers within a median delay of 1 hour, with a median time to telereader response of 4.5 hours. 
To address membership concerns about WFPI's tele-expertise, we must put our work in context. Regarding our internal capacity, our international volunteer tele-reader numbers consistently outstrip current tele-expertise demand. In terms of functionality, the Collegium Telemedicus platform is purposely constructed for store-and-forward telemedicine use in low-resource and low-Internet-bandwidth settings [20]. Its users' terms and conditions specify that studies sent to WFPI for a second opinion do not entail any transfer of legal responsibility from referrer to specialist.

Regarding fears of impeding onsite growth and development, WFPI's tele-expertise, delivered via bolt-on arrangements with non-governmental organizations such as Médecins Sans Frontières or RAD-AID, or directly to health care facilities, is requested by telereferrers who are providing care in areas of the world short of qualified medical staff. Rare is the facility with a radiologist at hand. Most countries in Africa have fewer than 30 radiologists, and 14 have none [21]. Zambia, for example, offers four public-sector radiologists for an estimated population of more than 14.4 million (of which $47 \%$ is younger than 15 years) [22]. Rarer still is the facility offering a pediatric radiologist; for the entire African continent, only a handful exist [23]. Development is therefore needed but imaging, and particularly pediatric imaging, is low on most national health systems' priority lists. So if our tele-referrers find our expertise useful, then these are starfish we are happy to help save!

WFPI has not yet formally assessed its platform-based support. Médecins Sans Frontières, however, has conducted a comprehensive analysis of user feedback on its own tele-expertise service (which includes WFPI volunteers). It also uses the Collegium Telemedicus platform. The study shows that of 163 respondents ( $30 \%$ of the 548 referrers and specialists who were sent the survey), all recognized the benefits of providing access to specialist advice in lower-resource settings, where there is usually no alternative way of obtaining such expertise. Furthermore, the majority of referrers $(91 \%)$ stated that they found 
the advice received via telemedicine to be useful. The most common reasons for this were in providing reassurance for the referrer or patient, in changing the management of the patient, and in changing the diagnosis [24].

\section{Starfish saves started, a little way to go}

\section{Childhood tuberculosis (TB)}

Tuberculosis remains a global public health concern, with one-third of the world's population being infected. Its burden is enormous, and it ranks as the second leading cause of death from a single infectious agent, after the human immunodeficiency virus (HIV). In 2014 alone, an estimated 9.6 million people developed TB (14\% with HIV co-infection) and 1.5 million died from the disease. The same year, an estimated 1 million children became ill and 136,000 died from TB [25]. Apart from the illness and death this generates, undiagnosed and untreated children with TB perpetuate the cycle.

While progress on development of simpler diagnostic tools for childhood TB remains slow, imaging still plays an important role when reliable interpretation is at hand, which it frequently is not. Interpretation of chest radiographs in children suspected of having TB can be challenging, especially to clinicians and general radiologists who do not routinely review pediatric radiographs. The inherent difficulties in obtaining radiographs in a crying and moving child are compounded by the less-optimal X-ray machines and techniques sometimes used in medically underserved areas. In response, WFPI has assembled experts from the high-TB-burden countries of Africa, Asia and Latin America in an attempt to impact childhood TB imaging diagnosis in lower-resource settings [26]. The group offers a bimonthly series of open-access educational articles for wide dissemination, with three published to date [27-29]. The group also offers a TB imaging hotline for colleagues around the world. Suspected childhood TB cases are referred from partners to the hotline's moderators, who forward the cases to the 19 members of the TB group. The final opinion is 
sent to the referral source within 24 hours. The TB hotline also serves as a forum for TB imaging experts to share and compare practice standards, with the cumulating cases providing valuable data for analysis. Thus practice modifications can be readily initiated with a consensus from experts. The development of a standardized reporting template is another major TB group drive.

The website traffic to our TB Corner, the open articles produced to date, our collaboration with the International Society of Radiology for its online TB educational model [30], and our hotline support for different tele-referring centers (Lao Friends Hospital for Children, Maputo General Hospital, Médecins Sans Frontières project sites) are an encouraging start. But this group's success lies in the take-up; expansion is a priority.

\section{Fostering the use of ultrasound in lower-resource settings}

Ultrasound is an ideal imaging tool for underserved community health care clinics because it is relatively affordable and safe, can be used by non-radiologist physicians trained in its use, has a multitude of uses for children and adults, and can be used in difficult terrain because it has portable forms. Because pneumonia continues to be a leading cause of pediatric morbidity and mortality in lower-resource settings, chest US is an emerging application of particular interest.

While the rapid evolution of this tool is exciting, delivering quality studies is crucial. WFPI can play a useful role in addressing the barriers to application — in print, online and onsite (while clinicians with short-focused training may have a high success rate for diagnosing pneumonia using ultrasound [31], onsite training does play a vital role in these developments [32]). To date, WFPI ultrasound endeavors roll out through bolt-on affiliations with non-governmental organizations (Médecins Sans Frontières’ field manual, Médecins Sans Frontières and Lao Friends Hospital for Children tele-expertise, onsite training in 
Uganda and Malawi with Imaging the World). With a working group established, WFPI also seeks to collate relevant literature and information on research and development, track pediatric radiologists worldwide who are involved, facilitate communication among them, and leverage resources for increased engagement and impact (Fig. 4).

\section{Producing guidelines/papers on pediatric topics}

While guidelines on pediatric topics of global concern and interest would have value, as one SPR member stated, "international consensus on guidelines that will have an impact is virtually impossible" because of local practice conditions and realities. However, practical guidelines on imaging methods and applications are an area that WFPI and its members can positively impact. In 2015 a group of WFPI-recruited authors partnered with Médecins Sans Frontières in the production of a pediatric point-of-care US manual for use in the field (projects in 60 countries in 2014 [33]).

\section{Starfish saves to be strengthened: spreading child imaging radiation safety globally}

At its inception, worldwide child imaging safety was declared a priority by WFPI's governing board, and this was echoed by members' calls to boost child imaging safety around the world $[34,35]$. WFPI has been present in safety forums in South America (São Paulo, Buenos Aires, Santiago), Japan, Switzerland, Tanzania and Kenya, but there is now a need to coordinate comprehensive global promotion and support. Operating with partners such as the World Health Organization and the International Atomic Energy Agency, we need synergies to collate and share the tools developed by the child safety movements underway. The Image Gently Alliance [36] has evolved since its establishment in 2007 to comprise nearly 100 international organizations [37], for example, and the EuroSafe campaign in Europe was formed in 2014. AFROSAFE in Africa [38], the LATINSAFE campaign (including South America), Japan Safe and Canada Safe were all launched in 2015, while others are forming 
around the world. To further its goals, WFPI formalized its partnership with Image Gently in 2015 to assure efficient and effective messaging and content and resource utilization.

Because regular interactions will be needed, an Image Gently representative has also joined WFPI's governing board.

\section{Starfish saves for later, we hope: stimulating international research projects}

Although WFPI has yet not moved ahead in this domain, it still aims to foster efforts to narrow the 10/90 gap in health research, in which less than $10 \%$ of funds spent on health research target the health problems of low- and middle-income countries, which account for $90 \%$ of the global disease burden [39]. A simple and successful future avenue might be mentoring colleagues in low-resource settings to implement focused and regionally relevant research projects. Such partnerships might also help change the current paradigm whereby research questions and protocols are written, analyzed and published in high-income centers while the data are collected by those at low- and middle-income centers [40]. National academic leaders and institutions need to be involved if research is to be translated into clinical practice [41].

\section{Saving the starfish more effectively: connecting different partners}

Over and above the different facets of WFPI's work, we have seen a pragmatic added value of our organization emerge. Through our own member organizations — whose individual members belong to other groups - we often get to hear of what's going on and where. This gives WFPI a unique overview of outreach work in our pediatric imaging community. We do not intend to coordinate these disparate efforts, but in an aid arena stymied by weak coordination and duplication [42], WFPI can use its information to encourage results and resources to be shared. Ultimately, it is unlikely that health care workers and patients in 
lower-resource settings have strong opinions about who delivers the aid; they just need it delivered effectively. Stretching the marine life theme a little further, we call WFPI's reach into multiple arenas our "tentacles" and our subsequent efforts to harness resources and reduce duplication our "octopus effect."

\section{Raising awareness of the saves: connecting further afield}

WFPI is well-positioned to channel and support the work of its national and regional member societies through diverse forums. Such efforts have included WFPI's own minisymposium published in Pediatric Radiology in May 2014 [43], the South African Journal of Radiology's special issue dedicated to pediatric imaging, produced for the International Day of Radiology 2015 in collaboration with SASPI [44], and the online International Day of Radiology 2015 pediatric imaging book, The Gentle Way, authored by an international group [45]. We regularly share events through social media, our website and newsletters, including our member societies' annual meetings and courses, and the different society and institutional activities promoting the 2015 International Day of Radiology's pediatric theme [46]. We also strive to ensure representation at global imaging meetings (RAD-AID's annual conferences, November 2014 and November 2015, for example).

WFPI mainly relies on social media to disseminate its news - both within and beyond pediatric radiologist circles. Our largest following is on Facebook, with 2,100 "likes" — a figure that doubled during the International Day of Radiology 2015 week (Fig. 5).

Graphics available via Facebook Insights throw light on the demographic of our social media audience, which reflects social media use at large. Most people are ages 25-34 years, with a steep drop-off after 44 . Hailing from 45 countries to date, they include a mix of radiologists, trainees and other health care professionals.

WFPI's website attracted 11,000 users to view 30,000 pages in 2015 . The most 
viewed pages to date include International Day of Radiology 2015 activities, newsletters, TB Corner, outreach tele-reading/training and worldwide educational initiatives as well as the portal to the YouTube online video library and educational links. With traffic rising throughout the year, posts on the International Day of Radiology 2015 activities attracted a tenfold-increase traffic spike.

WFPI also issues quarterly newsletters [47] (12 issued to date), circulated via our social media outlets and member organizations. For the latter, forwarded circulation to individual physicians is highly variable because it depends on societies' own communication with their members.

WFPI's International Day of Radiology 2015 activities provide a salient example of connecting pediatric radiologists with the world — as well as marking a first for global participation in an international event under one pediatric imaging umbrella. Besides the "Case of the Day" initiative with Radiopaedia, WFPI hosted pediatric imaging photo and video contests through our social media outlets and website. “This father's powerful video has become an International Day of Radiology highlight" declared Radiopaedia, on sharing the winning trainee video [48] on Facebook. This video has since been viewed on YouTube more than 8,200 times. As the day itself rolled out, so did our online global wave [49]. Around the world in 24 hours, from Australia to Hawaii, pediatric radiologists celebrated their work, their departments and the 2015 International Day of Radiology pediatric theme in more than 70 team photos posted online by WFPI and forward-circulated with enthusiasm by our followers (Fig. 6).

It bears noting that WFPI's efforts had considerable influence on the 2015 International Day of Radiology's visibility, contributing to the sharp rise in Twitter-based tweets using the \#IDoR2015 hashtag (3,980 in 2015 compared to 1,825 the previous year) (Fig. 7). We connected! 


\section{Clearing the beach: lessons learned and challenges}

We have seen how demanding it can be to chart the course and set priorities, to keep ambitions unwaveringly commensurate with our means. From fund-raising to the deep complexity of delivering medical aid, international organizations are constantly grappling with internal and external challenges [50]. And fund-raising is indeed a challenge for WFPI. Stand-alone individual project work is considerably easier to finance than communication and collaboration among physicians and assisting others in making the starfish saves. But such comprehensive project work vastly outstrips our ambitions, time and expertise. The consequent limits on our resources render the honing and re-honing of our mandate critical.

In online education, it has been a challenge eliciting members to contribute cases and to encourage their trainees to use our resources. Nonetheless, the countries reached by our video library in just 12 months and the 2 million health workers' screens reached by the International Day of Radiology 2015 cases of the day underscore the potential of our online presence. Development must now be bolder and better-resourced. Lack of engagement of more experienced radiologists becomes an issue in content creation because our younger users could benefit greatly from their experience if it could be captured. This calls for a proactive recruitment strategy. Furthermore, social media reach to Asian countries such as China and Japan has been more difficult because this region uses WeiBo and other social media channels more often than Facebook or Twitter; WFPI aims to explore a cross-channel reach with our Asian society members. Our data also show that our website needs heightened visibility, for example by linking communications and popular WFPI social media offerings back to the site, with regular new content to boost re-visits.

Regarding outreach, our greatest challenge lies in identifying bolt-on partnerships that achieve concrete results. Our TB efforts are a case in point. While we see their usefulness in a 
difficult domain starved for better diagnostic alternatives, we must secure greater access to TB networks to ensure our output has impact. Our tele-expertise also needs to expand and diversify, framing constructive debate on its future through clear and rigorous programmatic evaluation.

\section{Conclusion}

It has taken WFPI time to mold its mandate, and our trajectory can never be fully pre-set; our resources are constantly shifting and we operate within a fast-changing world. But we have reason to aim high. For WFPI is not just a coterie of well-intentioned and concerned citizens, but a group of professionals with a great deal of content expertise. Five years into its existence, WFPI seeks to create tools and generate resources that can be leveraged by multiple groups to be used wherever the need or desire for that expertise arises — whether that is high-resource settings, middle income, or low (with a particular focus on low, given the massive imbalance of global resources and the high number of children living in these areas). And while this choice might not have the direct feel-good nature of a more focused or direct intervention, it is nonetheless relevant and impactful and has the chance to make change at scale. In its self-styled octopus role, WFPI can keep hold of the big picture, reduce naivety, provide tools and raise the chances of success in the international work its members choose to undertake.

In the last 5 years WFPI has seen this wish becoming action, with plenty of opportunities ahead. On the review of the available member societies' opinions and the accomplishments to date, we believe that WFPI can go even further. Moreover, the worldwide celebrations of the 2015 International Day of Radiology demonstrated true unity of purpose in this global drive. Communication and collaboration delivered with such passion and pride can only spur WFPI on to achieve its goals. For their part, the authors of this paper 
— speakers of more than 20 languages and prime examples of global mobility — can affirm that the torch of international enthusiasm ignited by WFPI's founders continues to burn bright (Fig. 8).

Acknowledgments The authors thank the WFPI Council Executive Committee 2015-2016 members for reviewing the manuscript and approving its content. These members include Dorothy Bulas, Timothy Cain, Veronica Donoghue, Jaishree Naidoo, Rutger-Jan Nievelstein, Gloria Soto and Kimberly Applegate. The authors also extend their thanks to Richard Barth, MD (chair of SPR 2014-2015) and Jennifer Boylan (executive director of SPR) for releasing the SPR survey data for this paper.

\section{Compliance with ethical standards}

\section{Conflicts of interest None}

\section{References}

1. Adapted from "The Star Thower" from "The Unexpected Universe" by Loren Eiseley. Copyright (C) 1968 by Loren Eiseley and renewed 1996 by John A. Eichman, III. Used by permission of Houghton Mifflin Harcourt Publishing Company. All rights reserved.

2. A history of WFUMB and its presidents, $\mathrm{p} 5$. http://www.wfumb.org/about/presidents.pdf. Accessed 20 January 2016

3. Okma KG, Kay A, Hockenberry S et al (2015) The changing role of health-oriented international organizations and nongovernmental organizations. Int J Health Plann Manage [Epub ahead of print]. doi: 10.1002/hpm.2298 
4. Melber H (2011) Global governance: ‘to save us from hell.’ $D+C^{E+Z}$. http://www.dandc.eu/en/article/lasting-lecagy-un-general-secretary-dag-hammarskjold50-years-after-his-death. Accessed 20 January 2016

5. (2015) Bylaws of the World Federation of Pediatric Imaging. WFPI website. http://www.wfpiweb.org/Portals/7/About/FINAL_WFPI_Bylaws_revised_April2015.pdf. Accessed 20 January 2016

6. (2012) Strategic framework. World Federation of Pediatric Imaging. WFPI website. http://www.wfpiweb.org/Portals/7/About/WFPI_Strategic\%20Framework\%20_Full_versi on.pdf. Accessed 20 January 2016

7. (2015) Feedback from WFPI regional/council member organizations on 'WFPI - what future?' WFPI website.

http://www.wfpiweb.org/Portals/7/Workrooms/Feedback,\%20regional\%20boards\%20\%20\%20WFPI,\%20what\%20future-.compressed.pdf. Accessed 20 January 2016

8. (2015) Radiologists and trainees. CHOP radiology webinars for South Africa via the World Federation of Pediatric Imaging website.

http://www.wfpiweb.org/EDUCATION/Radiologiststrainees.aspx\#CHOPwebinars Accessed 20 January 2016

9. (2015) WFPI education channel. World Federation of Pediatric Imaging web site. http://www.wfpiweb.org/EDUCATION/PortalWFPIYouTubeeducationchannel.aspx. Accessed 20 January 2016

10. (2016) Radiopaedia web site. www.radiopaedia.org. Accessed 20 January 2016

11. (2015) Pediatric imaging cases - WFPI — IDOR 2015. Radiopaedia web site. http://radiopaedia.org/playlists/4415. Accessed 20 January 2016 
12. (2015) Looking to affiliate an outreach project with WFPI? -World Federation of Pediatric Imaging web site. http://www.wfpiweb.org/OUTREACH/Projectapproval.aspx. Accessed 20 January 2016

13. Mollura DJ, Azene EM, Starikovsky A et al (2010) White paper report of the RAD-AID Conference on International Radiology for Developing Countries: identifying challenges, opportunities, and strategies for imaging services in the developing world. J Am Coll Radiol 7:495-500

14. (2016) RAD-AID web site. http://www.rad-aid.org. Accessed 20 January 2016

15. Darge K, Gorfu Y, Jaramillo D (2014) Ethiopia: who to educate, how to educate and what to teach. Pediatr Radiol 44:642

16. (2015) Addis Ababa, Ethiopia: pediatric radiology fellowship. World Federation of Pediatric Imaging website.

http://www.wfpiweb.org/OUTREACH/WorldwideEducationalInitiatives.aspx\#Ethiopia. Accessed 20 January 2016

17. Griggs R, Andronikou S, Nell R et al (2014) World Federation of Pediatric Imaging (WFPI) volunteer outreach through tele-reading: the pilot project in South Africa. Pediatr Radiol 44:648-654

18. (2016) Collegium Telemedicus web site.

http://collegiumtelemedicus.org/ct/information.php. Accessed 6 February 2016

19. Nijssen-Jordan C (2015) Letter of support for WFPI's nomination for the 2016 American College of Radiology Foundation's Global Humanitarian Award. http://www.wfpiweb.org/Portals/7/Outreach/LOAS\%20WFPI\%20Support\%20letter.pdf. Accessed 20 January 2016 
20. Wootton R, Wu WI, Bonnardot L (2013) Nucleating the development of telemedicine to support healthcare workers in resource-limited settings: a new approach. J Telemed Telecare 19:411-417

21. Andronikou S, McHugh K, Abdurahman N et al (2011) Paediatric radiology seen from Africa. Part I: providing diagnostic imaging to a young population. Pediatr Radiol $41: 811-825$

22. (2016) Country reports: Zambia. RAD-AID website. http://www.rad-aid.org/resourcecenter/country-reports/. Accessed 20 January 2016

23. Andronikou S (2014) Unique issues in Africa. http:// www.pedrad.org/Portals/5/Events/2013/AndronikouAfrica.pdf. Accessed 20 January 2016

24. Bonnardot L, Wootton E, Liu J et al (2015) User feedback on the MSF tele-expertise service after a 4-year pilot trial — a comprehensive analysis. Front Public Health 3:257

25. World Health Organization (2015) Disease burden and 2015 targets assessment. In: Global tuberculosis report 2015. World Health Organization, Geneva, pp 13-34. http://www.who.int/tb/publications/global_report/en/. Accessed 20 January 2016

26. (2015) TB corner. World Federation of Pediatric Imaging website. http://www.wfpiweb.org/OUTREACH/TBCorner.aspx. Accessed 20 January 2016

27. Laya BF, Santo Domingo CL, Javier XM, Sanchez M (2015) Drug resistant tuberculosis: radiologic manifestations. WFPI TB corner. http://www.wfpiweb.org/Portals/7/Outreach/DR-TB-Imaging-Final.pdf. Accessed 20 January 2016

28. Tatco VR, Mejia-Santos MM, Uy JAU (2015) The many faces of hepatic tuberculosis. WFPI TB corner. http://www.wfpiweb.org/Portals/7/Outreach/Hepatic-TB-Imaging.pdf. Accessed 20 January 2016 
29. Concepcion NDP, De Lima GU (2016) Chronic diarrhea : an unusual symptom of gastrointestinal tuberculosis. WFPI TB corner forum.

http://www.wfpiweb.org/Portals/7/Outreach/Chronic\%20Diarrhea\%20in\%20GI\%20TB\% 20-\%20TB\%20Forum.\%20Jan\%202016\%20final.pdf. Accessed 20 January 2016

30. (2015) WFPI collaboration with ISR — 'Imaging of tuberculosis.' International Society of Radiology and WFPI's online tuberculosis educational module. http://www.wfpiweb.org/OUTREACH/TBCorner.aspx\#ISR. Accessed 20 January 2016

31. Shah VP, Tunik MG, Tsung JW (2013) Prospective evaluation of point-of-care ultrasonography for the diagnosis of pneumonia in children and young adults. JAMA $167: 119-125$

32. Boechat I, Cain T (2015) President and treasurer's annual report, 2014-2015, slide 37. http://www.wfpiweb.org/Portals/7/About/Annual-President-Treasurer-Report-2014-2015WFPI-lite.pdf. Accessed 20 January 2016

33. Médecins Sans Frontières/Doctors Without Borders (2014) MSF international activity report 2014. http://www.msf.org/msf-international-activity-report-2014. Accessed 20 January 2016

34. (2012) WFPI-RSNA (Chicago), $26^{\text {th }}$ November 2012, 07:30 local time: minutes. World Federation of Pediatric Imaging and Radiological Society of North America meeting minutes. http://www.wfpiweb.org/Portals/7/About/Minutes\%20RSNA\%202012\%20.pdf. Accessed 20 January 2016

35. (2014) Developing the framework of the global federation of pediatric radiologists. Internal WFPI report. January 2014, p 5. http://www.wfpiweb.org/Portals/7/About/WFPI_Report_Jan_2014_REF_Capital_Injectio ns.pdf. Accessed 20 January 2016 
36. (2014) Image Gently: The Alliance for Radiation in Pediatric Imaging web site. http://www.imagegently.org. Accessed 5 February 2016

37. Strauss KJ, Frush DP, Goske MJ (2015) Image Gently campaign: making a world of difference. Med Phys International 3:94-108

38. (2015) About AFROSAFE - Africa-wide campaign on radiation safety.

http://www.wfpiweb.org/Portals/7/Child\%20Imaging\%20Safety/BRIEFING\%20about\%2 0AFROSAFE.pdf. And AFROSAFE implementation tool matrix.

http://www.wfpiweb.org/Portals/7/Child\%20Imaging\%20Safety/afrosafe\%20implemanta tion\%20matrix\%201.pdf. Both accessed 20 January 2016

39. Nuyens Y (2007) Setting priorities for health research: lessons from low- and middleincome countries. Bull World Health Organ 85:319-321

40. Zar HJ (2014) Partnering with centers of excellence in high- and low-middle-income countries: a strategy to strengthen child health globally. Pediatr Radiol 44:709-710

41. Andronikou S, Mngomezulu V (2011) Paediatric radiology seen from Africa. Part II: recognising research advantages in a developing country. Pediatr Radiol 41:826-831

42. Kopinak JK (2013) Humanitarian aid: are effectiveness and sustainability impossible dreams? J Human Assist. https://sites.tufts.edu/jha/archives/1935. Accessed 20 January 2016

43. (2015) WFPI mini-symposium: outreach in the developing world, issued May 2014. http://www.wfpiweb.org/Home/WFPIMiniSymposium.aspx. Accessed 20 January 2016

44. Davis R (2015) Paediatrics edition, S Afr J Radiol http://www.sajr.org.za/index.php/sajr/issue/view/53. Accessed 20 January 2016

45. European Society of Radiology (2015) The gentle way: the art of paediatric imaging. http://www.myesr.org/start/IDoR2015/IDoR2015_Paediatric\%20Imaging\%20Book_FIN AL.pdf. Accessed 5 February 2016 
46. (2015) IDoR celebrations from around the world. World Federation of Pediatric Imaging website. http://www.wfpiweb.org/ABOUT/IDoR2015pediatrics.aspx\#Africa. Accessed 20 January 2016

47. (2015) Newly issued: small world, WFPI's newsletter, December 2015. World Federation of Pediatric Imaging website.

http://www.wfpiweb.org/ABOUT/NewslettersArticles.aspx. Accessed 20 January 2016

48. Somcio R (2015) International Day of Radiology — my daughter. YouTube video. https://www.youtube.com/watch?v=kleCnZUunSU\&feature=youtu.be. Accessed 20 January 2016

49. (2015) International Day of Radiology: the global pediatric radiology wave. http://www.sorantin.com/IDoR/. Accessed 20 January 2016

50. Rogerson A (2004) Working paper 235. The international aid system 2005-2010: forces for and against change. Overseas Development Institute, London. http://www.odi.org/sites/odi.org.uk/files/odi-assets/publications-opinion-files/2033.pdf. Accessed 20 January 2016

\section{Legends}

Fig. 1 Drawing provided by Pascal Elie (C) WFPI World Federation of Pediatric Radiology Fig. 2 Graph shows YouTube top 10 countries, "watch time" (in hours), for viewers of the WFPI/SPR online video library. WFPI World Federation of Pediatric Radiology, SPR Society for Pediatric Radiology

Fig. 3 Radiopaedia/WFPI case reach in November 2015. Graph shows a spike on the International Day of Radiology 2015. WFPI World Federation of Pediatric Radiology Fig. 4 Photograph of WFPI working onsite: Dr. Tracy Kilborn, MBChB, FRCR (Cape Town, South Africa) trains Peter Maseko, clinical officer in pediatric ultrasound at Pothawira Clinic, 
Salima, Malawi, in 2014. This project was run by Dr. Kay North, DO (Kansas, USA), of Imaging the World. WFPI World Federation of Pediatric Radiology

Fig. 5 WFPI Facebook page "likes" on Nov. 10, 2015, during International Day of Radiology celebrations. WFPI World Federation of Pediatric Radiology

Fig. 6 Collage of photographs of radiology staff around the globe, taken during the International Day of Radiology 2015 Global Wave

Fig. 7 Twitter screenshot shows influencers during the International Day of Radiology 2015 celebrations

Fig. 8 Drawing provided by Pascal Elie $(\mathrm{C}$ 


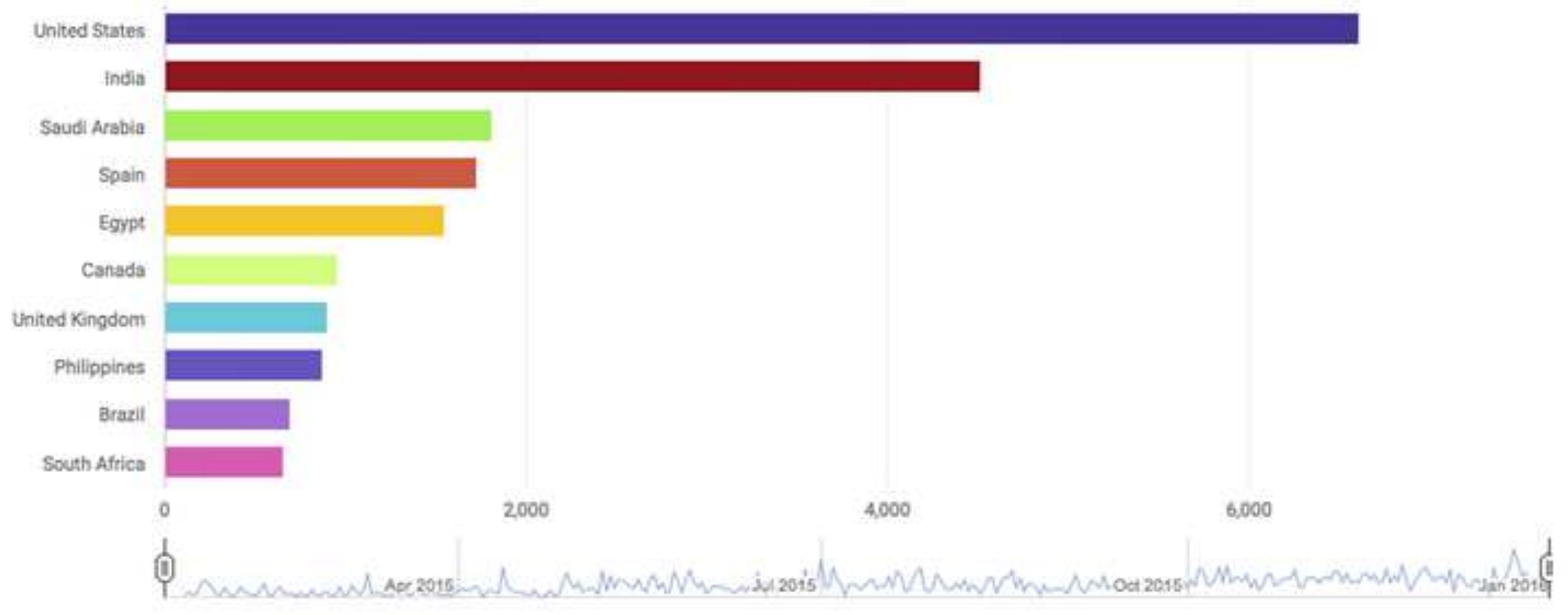

Watch time (in hours) 


\section{$2,102,989$}

Total Reach

- $50.2 \%$

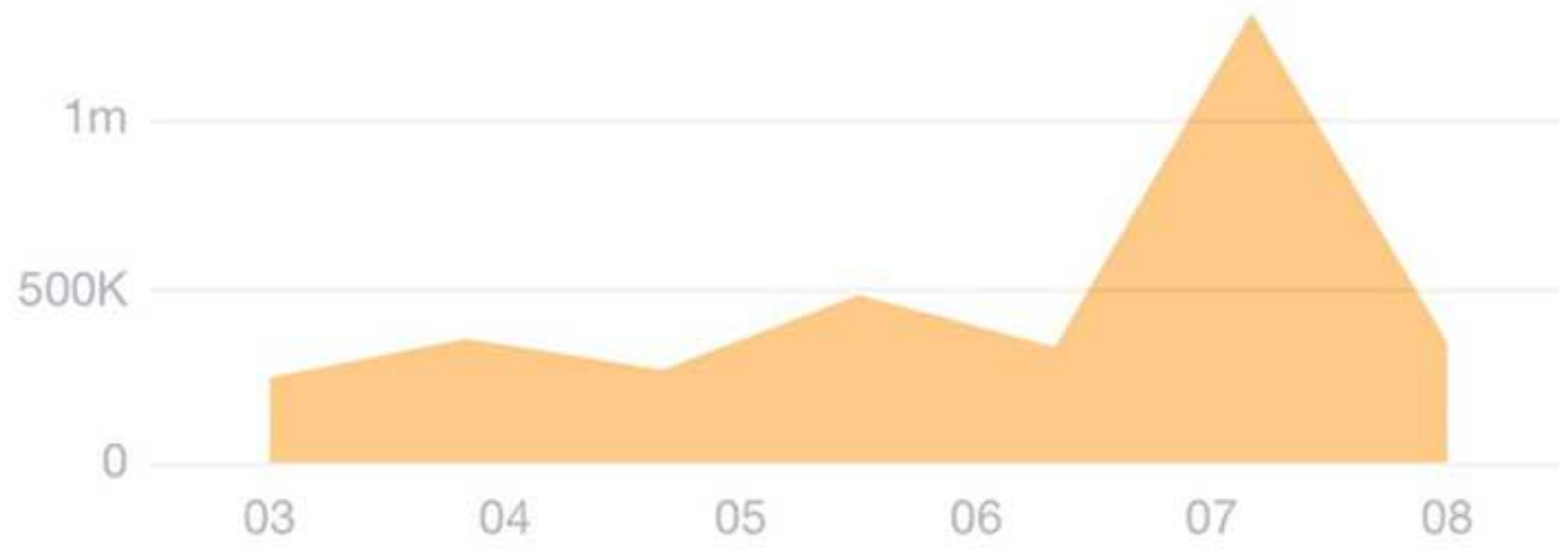

Dates, November 2015 
Click here to download Figure fig 4.tif $\underline{\underline{ }}$

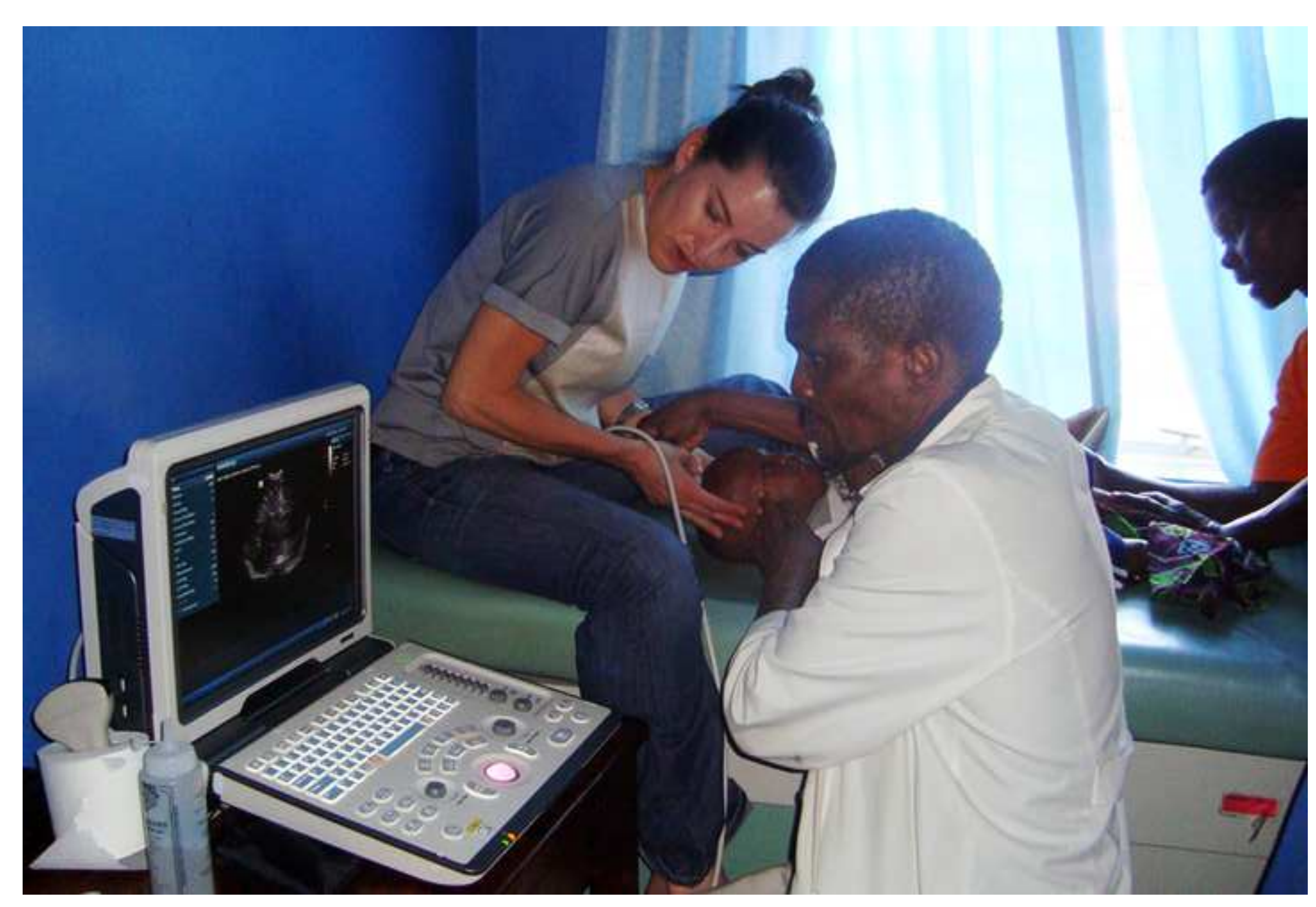




\section{Total Page Likes as of Today: 1,974}

- Total Page Likes

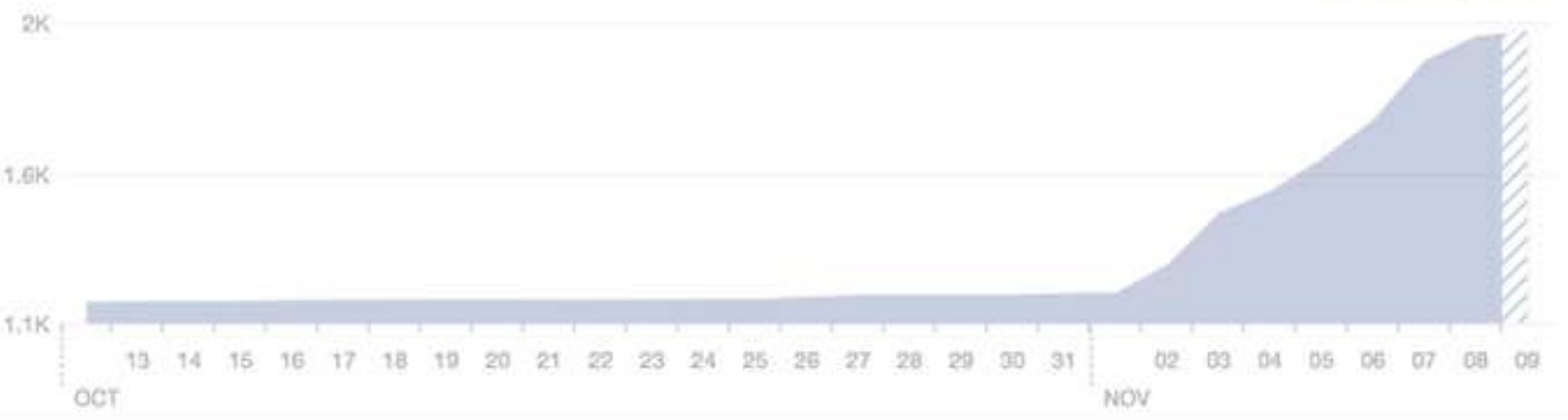




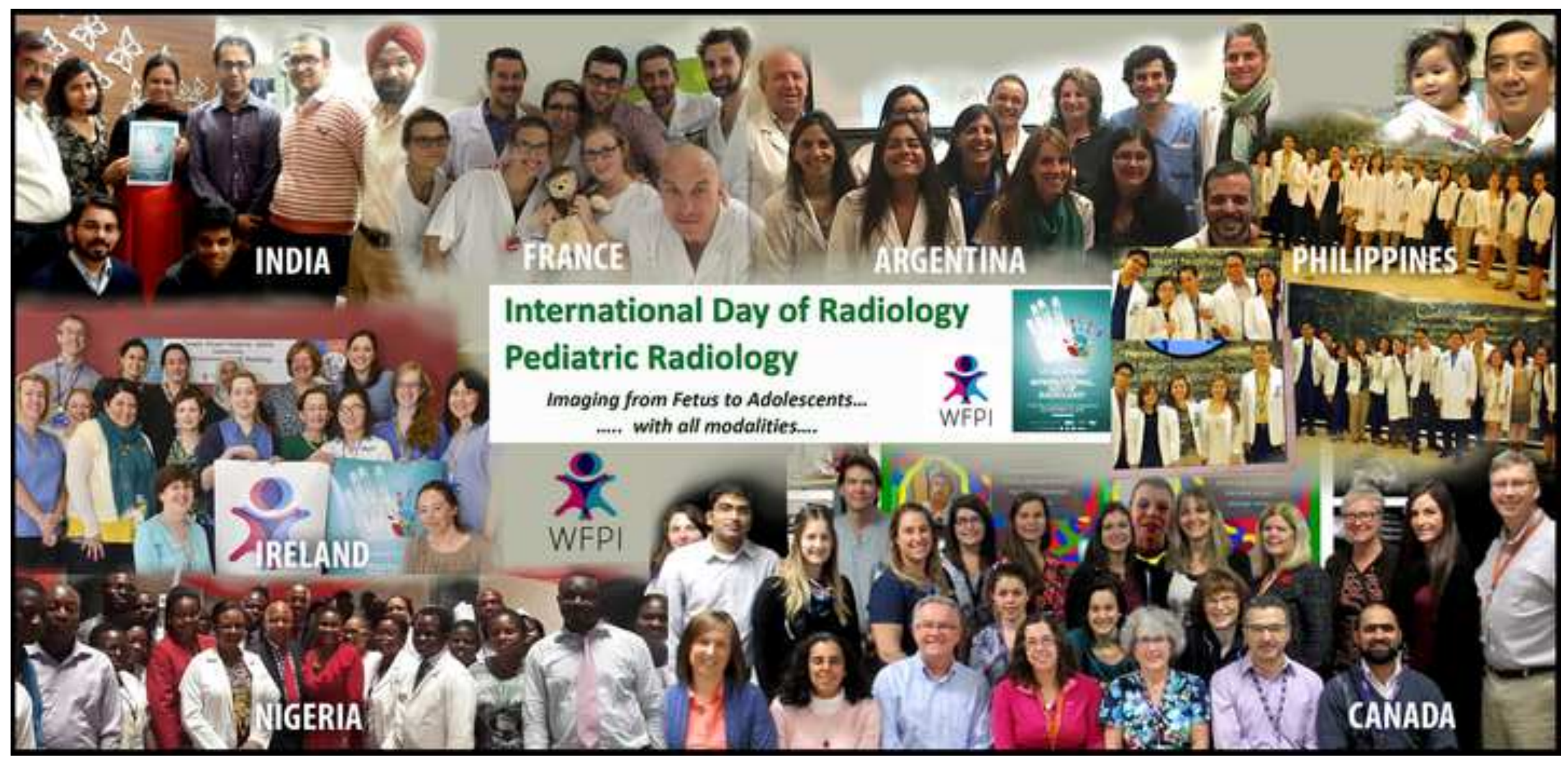




\section{The \#IDor2015 Influencers}

\section{Top 10 by Mentions}

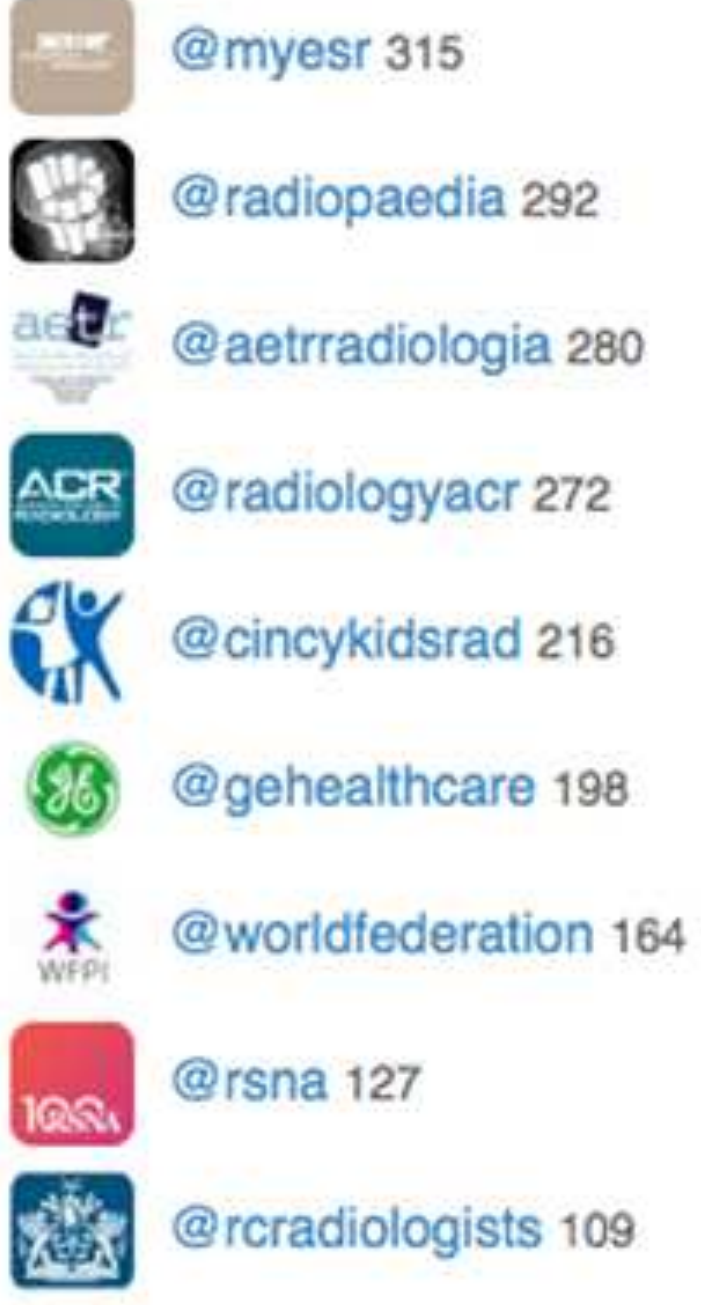

In:as@amnakashgari 102

\section{Top 10 by Tweets}

@jorgear05208958 124

충worldfederation 108

Aly @ cincykidsrad 105

oeore @segraradiologia 99

(ii) @ @igure1 88

ACR @ radiologyacr 67

@ jamadorg 63

@ehealthmgmt 48

(2) @rayoscoimbra 46

a@E@aetrradiologia 46 


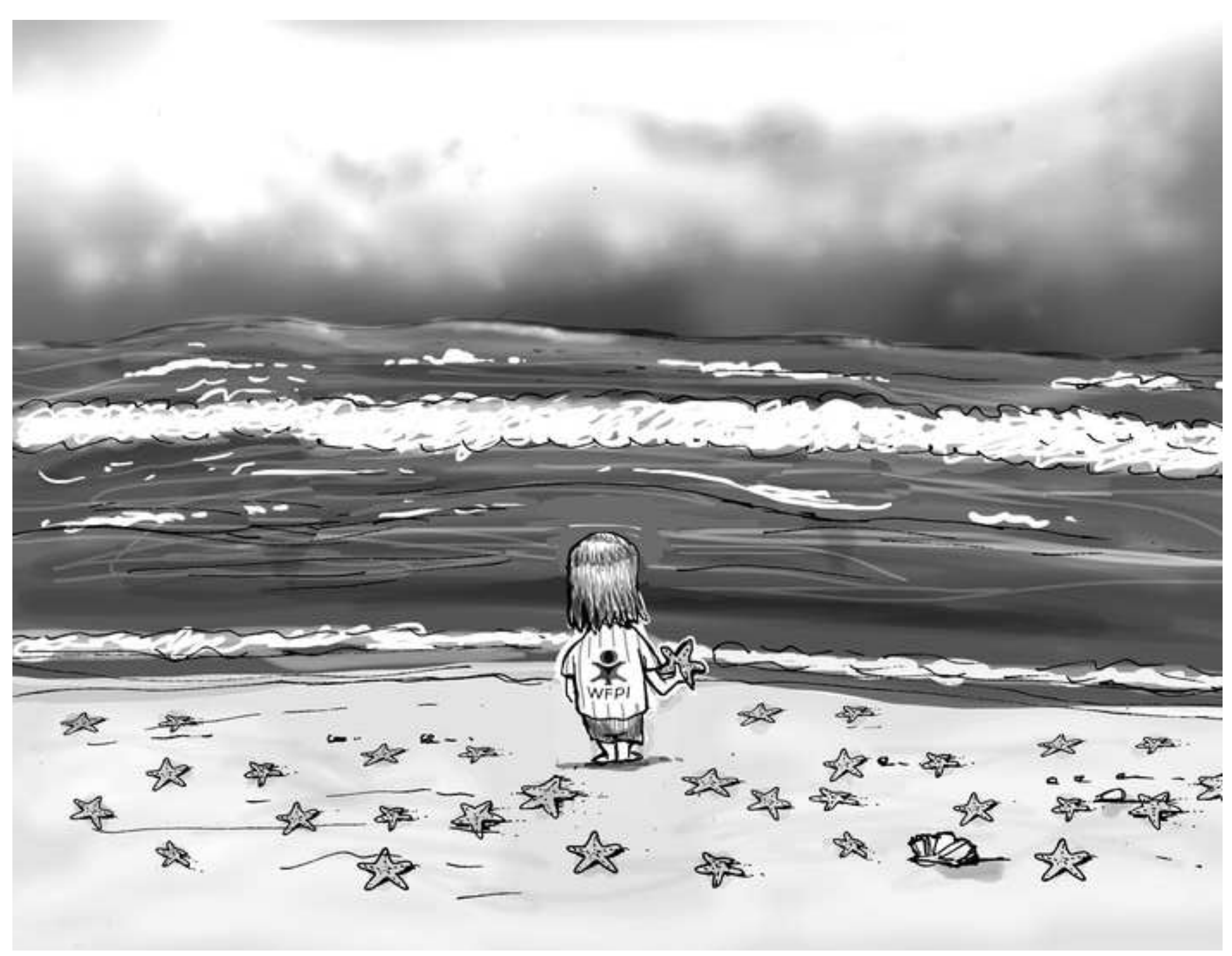

.

(

.

